\title{
Globalização, aprendizagem e trabalho docente: análise das culturas de performatividade*
}

\author{
Globalization, learning system and teaching work: cultural analysis \\ of standardization
}

\author{
La globalización, el aprendizaje y la enseñanza: análisis de las \\ culturas de la performatividad
}

JOSÉ A. PACHECO**
TÂNIA PESTANA***

$\diamond$

\begin{abstract}
RESUMO - Nos modelos de regulação transnacional e supranacional, as políticas de partilha de conhecimento definem não só processos de regulação cognitiva, em que a mudança se impõe pela via conceitual, mas também práticas de avaliação centradas nos testes, no quadro de uma avaliação externa das instituições, dos professores e dos alunos. Aceitando-se como válida a asserção de que as escolas, em geral, e a educação básica, em particular, são confrontadas com um modelo pós-burocrático de gestão, indutor de estandardização de resultados, o artigo contém uma análise, por um lado, de que modo as políticas educativas, moldadas pela globalização, reforçam uma abordagem centrada nos testes, e por outro, em que sentido essa mesma abordagem introduz alterações significativas na aprendizagem discente e no trabalho docente. Finalmente, conclui-se que a globalização interessa as políticas de educação na forma de políticas viajantes, definindo processos e práticas de avaliação que conduzem à performatividade das aprendizagens e à desqualificação docente.
\end{abstract}

Palavras-chave - Globalização. Aprendizagem. Trabalho docente. Testes.

\begin{abstract}
Global policies on education reveal not only the regulation of cognitive processes, but also practical assessment focused on tests, not only to evaluate and adjust students' learning, but also the proficiency of the teachers themselves. On accepting as valid the idea that schools and basic education are confronted with a model beyond the bureaucratic system, aiming the standardization of results, this article focuses on an analysis of educational policies shaped by the globalization, focusing on tests, and reflects in what sense this approach inserts significant changes in student learning and teaching. Finally, we concluded that globalization interferes with the education policy in terms of travelling policies, defining processes and assessment practices that lead to the learning's standardization and teachers' disqualification.
\end{abstract}

Keywords - Globalization. Learning. Teacher Work. Test.

RESUMEN - En los modelos de regulación transnacional y supranacional, las políticas para el intercambio de conocimiento no sólo definen los procesos de regulación cognitiva, cuando estos se imponen por la vía conceptual, sino también las prácticas de evaluación se centran en las pruebas, como parte de una evaluación externa de las instituciones, los profesores y los estudiantes. Aceptando como válida la afirmación de que las escuelas en general, y la educación básica, en particular, se enfrentan a un modelo de gestión post-burocrática, lo que induce la normalización de los resultados, este artículo ofrece un análisis, por una parte, de cómo las políticas educativas, son modeladas por la globalización, el fortalecimiento de un enfoque centrado en las pruebas, y por otra parte, en como este enfoque introduce cambios significativos en el aprendizaje de los alumnos y el trabajo docente. Por último, llegamos a la conclusión que la globalización interfiere en las políticas de educación como políticas cambiantes, procesos que conducen a prácticas de evaluación que llevan a la estandarización del aprendizaje y la inhabilitación de los docentes. Palabras clave - Globalización. Aprendizaje. Trabajo docente. Pruebas.

\footnotetext{
* Este trabalho é financiado por Fundos FEDER através do Programa Operacional Fatores de Competitividade - COMPETE e por Fundos Nacionais através da FCT - Fundação para a Ciência e a Tecnologia no âmbito do projeto PTDC/CPE-CED/116674/2010.

** Doutor em Educação pela Universidade do Minho (Braga, Portugal) e Professor na Universidade do Minho (Braga, Portugal). E-mail: <jpacheco@iep. uminho.pt>.

***Doutoranda pela Universidade da Madeira (Funchal, Portugal). E-mail: <tpestana@outlook.pt>.
} 


\section{INTRODUÇÃO}

Admitindo-se que existe um processo global de governação, de que o neoliberalismo é o sistema fundador, pelo menos nas palavras críticas de Foucault (2010), para quem a racionalidade económica se transformou na matriz analítica da realidade social, as políticas de partilha em torno do conhecimento instituem-se como um referencial coercivo, em que as reformas são implementadas mediante "[...] políticas viajantes - não se sabe de onde vêm, nem para onde vão; elas são ao mesmo tempo as reformas de todos e de ninguém [...]" (STEINER-KHAMSI, 2012, p. 11) - e na base de uma linguagem técnica orientada por critérios de convergência. Assim, as reformas educativas convertem-se em reformas viajantes, sendo mais caraterizadas pelos aspetos que as unificam e tornam semelhantes do que pelos aspetos que as diferenciam. Interrogando-se a este respeito ANDERSON-LEVITT (2008, p. 349) questiona: "O que está realmente acontecendo? [...] Estarão o currículo e a instrução de facto a tornarem-se similares em todo o mundo?".

Aliás, esta tendência de convergência faz com que o processo de globalização caminhe em direção à homogeneização e similaridade, à partilha de standards e à intenção de criar um elevado grau de uniformidade, deixando como marcas distintas quer a imposição de um diálogo comum sobre as reformas, quer uma maior analogia mundial à volta do currículo prescrito (ANDERSON-LEVITT, 2008).

Porém, e como se vivenciam tempos de uma governação pós-burocrática, a estandardização de processos é substituída pela estandardização de resultados (MAROY, 2012) e a regulação normativa, na procura de uma conformidade de regras, é suplantada pela imposição cognitiva, de que os testes à larga escala são um exemplo no domínio do controlo das aprendizagens, tal como os mecanismos de avaliação institucional e de avaliação das aprendizagens, com prevalência dos olhares externos sobre os olhares internos (PACHECO, SEABRA, MORGADO e HATTUM-JANSSEN (2014), aliás, na base do conflito "entre dois logos e entre dois registos de palavras" (SOBRINHO, 2003, p. 149), isto é, entre o objetivo/subjetivo, o quantitativo/qualitativo e o sumativo/ formativo. Sustentamos neste artigo que as práticas em curso de reforma educacional, afetas a uma cultura de avaliação de prestação de contas e de responsabilização (AFONSO, 2012), por sua vez definida pela globalização, têm como sustentáculo a estandardização dos resultados de aprendizagem, o que origina uma mudança no trabalho docente e no modo como a aprendizagem é valorizada no âmbito das decisões curriculares, sobretudo quando impera a lógica dos testes. Entendemos, por conseguinte, que a abordagem de currículo centrada nos testes é essencialmente definida pela abordagem centrada em resultados e pela abordagem centrada em standards, ou seja, formas de governamentalidade curricular expressas nas práticas quotidianas da educação escolar, cada vez mais inseridas numa lógica empresarial para a educação (KARP, 2012), em normas concretas para a privatização das escolas (GUISBOND, NEILL e SCAEFFER, 2012) e em práticas de mercadorização curricular. O artigo está estruturado em quatro pontos: 1) modelos de governação; 2) abordagem centrada em resultados de aprendizagem; 3) abordagem centrada em standards; 4) escolarização restrita.

\section{MOdELO DE GOVERNAÇÃo}

Dentro do que Maroy (2012) apelida de modelo pósburocrático de governação, que se contrapõe ao modelo burocrático de base normativa, as novas formas de governamentalidade são impostas pela estandardização de resultados, em que ganha sentido a conceção de escola regulada por fatores de produtividade. É este modelo de mercado (ou de quase-mercado) que possibilita "[...] a educação de prestação de contas como um processo de governação global" (ibid., p. 91), transferindo para a escola e para os seus atores a responsabilidade, tornando-se quer numa linguagem atrativa para ativistas, professores e pais, quer num instrumento de meritocracia escolar, quer, ainda, nos alicerces de privatização da educação (TAUBMAN, 2009). Perfilhando-se que "a sociedade não tem uma necessidade indefinida de conformidade" (FOUCAULT, 2010, p. 320), a escola, paralelamente a outras instituições sociais, revela-se consumidora de comportamentos conformes a gramáticas políticas, onde coexistem regras formais e informais, embora a racionalidade económica imponha uma conformidade dinâmica e pragmática, com tendência para a existência de uma estrutura invariante na forma escolar e na ação dos professores.

No estudo das conformidades escolares, verifica-se que o século XX foi, na sua generalidade, um tempo de conceção e aplicação à educação de quadros teóricos sobre a gestão científica da educação, de natureza eficientista e pragmatista, na busca da eficácia escolar (BROOKE e SOARES, 2008), acrescentando o mercado, desde as duas últimas décadas, a conformidade dinâmica que se traduz na permanente inovação competitiva. Por isso, o lado económico da educação é algo que permanece desde a institucionalização da escola pública, tornada obrigatória pelos diversos regimes políticos, pois, para além dos propósitos pedagógicos, a escola responde a finalidades económicas, sociais, culturais e políticas. Conforme refere Charlot (2007, p. 128), a escola tem sido pensada numa lógica económica, facto esse que aconteceu nas décadas 
de 1960 e 1970, "na época do Estado Desenvolvimentista, antes da globalização", e que se reforçou na década de 1980, no quadro das "lógicas da qualidade, da eficácia e da territorialização", originando o nascimento do Estado Regulador.

Tendo como referência a tendência para a mercadorização da educação, a globalização, em geral, e as políticas de partilha de conhecimento, em particular, têm impacto e produzem efeitos nas aprendizagens escolares e no trabalho docente, para além de gerarem dispositivos de recentralização do currículo e de tornarem mais presentes e acutilantes modelos externos de avaliação, tanto das aprendizagens como das instituições escolares. Neste sentido, reconhece-se que é o mercado, como ideia estruturante das políticas de educação e formação, que introduz regras bem explícitas na engrenagem social, tornando a educação numa variável económica, suscetível de ser regulada pelas leis de oferta e procura, tal como se encontra no neoliberalismo educacional e nas consequentes formas concretas de governamentalidade curricular que derivam da abordagem centrada nos testes.

\section{Abordagem Centrada EM RESULTADOS DE APRENDIZAGEM}

A abordagem centrada em resultados de aprendizagem tem uma estruturação quer conceitual, fazendo parte do léxico da competitividade e do sucesso, para além de outros, os termos qualidade, eficácia, eficiência, performance, competência e testes (TAUBMAN, 2009; RIZVI e LINGARD, 2010), quer procedimental, com a realização de estudos internacionais comparativos, seriação de escolas, testes nacionais finais/intermédios e programas de orientação curricular centrados em disciplinas-chave (TAUBMAN, 2009; FREITAS, 2012). Trata-se de uma tendência curricular que traduz a conjugação da racionalidade tyleriana (SILVA, 2000) com a racionalidade mercantil, com vista à instauração da meritocracia como motor da competitividade educacional.

A medição da eficiência escolar processa-se, assim, pelos resultados de testes internacionais, ou de testes à larga escala, por exemplo The Programme for International Student Assessment (PISA), Programme for International Student Assessment Progress in International Reading Literacy Study (PIRLS), Trends in International Mathematics and Science Study (TIMSS), European Indicator of Language Competence (EICL). ${ }^{1}$ De entre estes, o que mais tem contribuído para o reforço da tendência curricular centrada em resultados tem sido o PISA, estabelecendo, de acordo com as ideias expressas por vários autores (PEREYRA, KOTTHOFF e COWEN, 2011; POPKEWITZ, 2011; LUNDGREN, 2011), não só uma governação por comparação de resultados, mas também uma competição baseada na seriação de países, não estando ligado ao que alunos aprendem, a partir de currículo nacional, nem tão pouco aos métodos de ensino/ aprendizagem utilizados nas salas de aula. Tendo-se tornado num modelo de governação curricular global, o PISA é um instrumento político, que pretende tornarse num instrumento de melhoria das escolas mediante a aplicação de testes e questionários, com supremacia para a avaliação de competências em função da preparação dos jovens para o mercado do trabalho e para a cidadania produtiva (OECD, 2012a).

Ao impor uma cultura de avaliação normativa, em que países e regiões são comparados por níveis de desempenho, os testes internacionais têm efeitos na avaliação sumativa, com preponderância para os testes nacionais, quer sejam finais e com peso ponderado na classificação final, quer sejam intermédios e com incidência na progressão dos alunos, pois o teste intermédio tende a ser utilizado nas escolas como teste substituto do teste elaborado pelo professor num dado período escolar, tal como está a acontecer na escola portuguesa. Deste modo, instala-se nas escolas a pressão junto dos professores, no sentido de prepararem os alunos para os testes padronizados (GUISBOND, NEILL e SCHAEFFER, 2012), em disciplinas que se tornam definidoras de um core curriculum, reconhecendo-se-lhes uma limitada autonomia pedagógica em termos de avaliação. No caso concreto português, os resultados dos alunos na avaliação sumativa externa (exames nacionais) tornam-se em dados estatísticos para a elaboração de seriações pelos mídia, sendo o tempo da sua divulgação um momento de glorificação da escola privada e de sacrificação da escola pública, como se as duas escolas tivessem os mesmos públicos escolares e a mesma realidade socioeconómica.

$\mathrm{O}$ ensino para os testes origina uma aprendizagem apressada, fazendo com que os professores se tornem em meros funcionários do ato pedagógico que acontece na sala de aula, reconhecendo Hargreaves e Fink (2007, p. 68), que "[...] vivemos em países com escolas apressadas", enchendo-se o currículo com mais conteúdos aferrolhados num tempo passado, fazendo-se mais testes e dando-se menos tempo aos alunos para responderem às questões. Por outro lado, e como se tornam em fatores de recentralização do currículo, os testes condicionam a autonomia pedagógica dos professores e impõem uma memorização a curto prazo (TAUBMAN, 2009).

Para lá desta linguagem dos testes, instala-se na escola a crença de que a meritocracia melhora com a privatização, em que a escola pública (no currículo e no financiamento) é administrada privadamente, no sentido de garantir a escolha como princípio regulador do mercado. Mas os dados sugerem que a "[...] manutenção destas políticas evidencia apenas a disposição ideológica 
de afirmar que o privado é melhor que o público [...]" (FREITAS, 2012, p. 385).

Desta abordagem curricular resulta a perspetivação do trabalho docente como uma atividade orientada para os resultados, transformando a aprendizagem em processos regulados pelos conteúdos das metas curriculares. Seguindo alguns dos fundamentos do programa governamental norte-americano "No Child Left Behind" (NCLB), lançado na década de 1990, Hargreaves e Fink (2007) reconhecem que a lógica produtivista da educação recrudesceu ao nível da escola, principalmente nestes efeitos: crise de diplomas; estreitamento e destruição da criatividade na sala de aula; restrição da capacidade distintiva das escolas inovadoras; alargamento do hiato na aprendizagem entre as escolas de elite e as outras; encorajamento de estratégias dissimuladas e calculistas para subir os resultados nos testes; alteração da confiança e competência dos professores; erosão das comunidades profissionais; aumento das taxas de estresse, de demissões e de baixa permanência no ensino; amplificação da resistência à mudança; acelerado carrossel de sucessões na liderança.

Mais do que simples retórica, a proposta de mudança em curso, e com reflexos evidentes nas políticas educativas portuguesas, por exemplo, através da promoção de estratégias estandardizadas de literacia (Plano Nacional da Leitura) e numeracia (Plano [de Ação] da Matemática), a cultura de testes e exames, o controlo e uniformização curriculares, a colaboração forçada, a queda dos resultados nas artes e humanidades, a obesidade dos alunos por falta de educação física, pelo que concluem os mesmos autores: "As evidências sobre os efeitos das reformas educativas impostas com firmeza, prescritas estritamente e implementadas com impaciência na América do Norte e em todo o mundo são consistentes e irrefutáveis [...] Apesar dos seus sucessos iniciais, "[...] a estandardização imposta a curto prazo e orientada para metas é, em última instância, insustentável [...]" (ibid., p. 26-27).

Ainda neste mar de obsessão pelo desempenho, o que interessa são os resultados e não os processos de aprendizagem, como se fosse possível, numa metáfora de Maurice Holt ${ }^{2}$ " [...] continuar a alimentar os alunos à força e depois esperar obter foie-gras [...]", atribuindose aos professores um papel relevante na aprendizagem. Porém, e citando um estudo sobre avaliação do desempenho docente, Guisbond, Neill e Schaeffer (2012, p. 419) referem que "os professores não são o fator mais importante no desempenho dos estudantes, o qual é essencialmente um produto das características do histórico do indivíduo e da família".

Ao inverter-se esta afirmação, a abordagem centrada nos resultados contribui para a desqualificação docente, precarizando e embaratecendo a profissão e fazendo crer que os testes são o principal motor das reformas a empreender e que o professor apenas precisa de ser formado no domínio dos conteúdos a ensinar e nas técnicas de ensino, pretendendo-se que sejam ignoradas as condições psicológicas e filosóficas do aprendente, a base sociológica da escola e o contexto histórico da construção do currículo nos seus diferentes contextos e níveis de decisão. Trata-se, assim, de uma perspetiva centrada na abordagem test-driven curriculum (PENNERWILLIAMS, 2010). Ao fazer a distinção entre "[...] avaliação como feedback e avaliação como condutor do currículo [...]", Young (2013, p. 111) argumenta que os professores "[...] estão cada vez mais pressionados a deslocar o sentido do papel da avaliação como feedback para o papel de prestação de contas como política de regulação do currículo".

\section{ABORDAGEM CENTRADA EM STANDARDS}

A abordagem curricular centrada em standards origina mudanças significativas na estrutura do processo de governação do currículo, naquilo que constitui a construção dos alicerces normativos ou das regras formais, bem como na referenciação do conhecimento, sobretudo se o currículo for entendido como um projeto de formação que acontece num dado espaço e num determinado tempo, servindo de ponte entre a esfera pública (social) e a esfera privada (pessoal) (PINAR, 2007).

Apesar da existência de diferenças regionais que englobam diversos países, o mercado segue a regra da padronização, princípio nuclear que está presente na estandardização curricular e que de modo eficientista conjuga conteúdos e desempenho. A ideia de performatividade curricular tem sido perseguida desde a génese da escola, com a identificação dos melhores ou piores alunos em função das suas capacidades e possibilidades, e consecutivamente reportada i) ao desenvolvimento cognitivo, como se a mente fosse um músculo, ii) à pedagogia por objetivos, na expressão do behaviorismo e do construtivismo, e iii) à pedagogia por competências. $\mathrm{O}$ mercado como matriz de solução educacional para os problemas económicos faz uma mescla destes movimentos, reafirmando-se como fundamento de uma pedagogia produtivista que é, ao mesmo tempo, eficiente na gestão e eficaz nos resultados, pois promove a escola como local de competitividade e responsabilização máxima dos professores.

A escola de mercado funciona na base de uma pedagogia produtivista que encontra no standard o critério da organização do currículo em função de uma linearidade factível e da reassunção da linguagem sistémica. Tal como na abordagem centrada nos resultados, os testes são o ponto essencial da abordagem baseada nos standards, 
tornando-se marcadores do processo de desenvolvimento do currículo, em geral, e da aprendizagem, em particular. Por isso, os resultados dos testes tendem a definir a realidade educacional (TAUBMAN, 2009), em que o valor dos números e da sua comparabilidade a nível nacional e internacional substituem os alunos, conferindo mais visibilidade aos resultados do que aos processos de aprendizagem. A linguagem dos testes, ou da proficiência e da performatividade da aprendizagem, processa-se na base de standards, que podem ser utlizados de diferentes modos na organização curricular, por exemplo, providenciando informação sobre o desempenho dos alunos, clarificando posições em tabelas comparativas de grupos, escolas e países e permitindo leituras sumativas e/ou formativas sobre as aprendizagens alcançadas pelos alunos.

Com efeito, o standard pode estar relacionado quer com objetivos comportamentais, metas curriculares e resultados de aprendizagem, quer com competências, sobretudo se estas disserem respeito a capacidades de utilização do conhecimento em contextos de ação. A noção de standard aplica-se ao objetivo, à meta e à competência, sendo sempre um processo de referencializar aspetos que contribuem para a mensuração do conhecimento. No que respeita à organização curricular ao nível do currículo nacional e dos planos que o materializam, $o$ standard é uma lógica que serve de referência para o estabelecimento de resultados esperados, isto é, de horizontes de aprendizagem de base que podem ser expressos em objetivos mínimos (em Portugal, com a designação de objetivos curriculares, na década de 1980), ou em competências transversais (na década de 2000), ou em metas curriculares (na década de 2010).

Os standards curriculares são um fator de homogeneização de programas e práticas de avaliação (MARADAN, 2008), no quadro de políticas educativas centradas nos resultados. Esta cultura de prestação de contas das escolas torna-se mais visível quanto mais for implementada uma prática de formulação e avaliação de indicadores de desempenho. Neste sentido, o currículo corresponde, cada vez mais, ao estabelecimento de resultados esperados, à listagem do que é esperado, à identificação de procedimentos pretendidos, à listagem daquilo que o aluno deve saber e fazer, à mensurabilidade do que deve saber, à identificação do que é fundamental saber e à demonstrabilidade do que realmente sabe. $\mathrm{O}$ fator comum a esta organização curricular diz respeito ao caráter finalizante do resultado de aprendizagem, o que faz com que a sua formulação corresponda a enunciados gerais e sintéticos sobre o que é esperado que o aluno venha a saber e fazer no final de um processo. Se no ensino superior, com o Processo de Bolonha, se utiliza a nomenclatura resultados da aprendizagem, nos ensinos básico e secundário faz-se uso, atualmente, das metas curriculares, entendidas como standards de conteúdos (SCALLON, 2009) e como objetivos terminais (PACHECO, 2011).

Os standards estabelecem o que se ensina e o que se aprende em contexto escolar, bem como os degraus desejáveis de proficiência. Além disso, “[...] normas servem para padronizar o trabalho, tornando-o comensurável, apagando as diferenças entre os indivíduos, população, histórias, locais" (TAUBMAN, 2009, p. 117). $\mathrm{O}$ estabelecimento de metas de aprendizagem (mensuráveis por níveis, ciclos e anos), o que está em sintonia com as políticas de educação que têm vindo a ser implementadas a nível internacional, servirá de referencial para a validação de modalidades de avaliação ligadas às classificações (avaliação sumativa), aos critérios (avaliação aferida) e à comparabilidade nacional e internacional (avaliação normativa). Por isso, poder-se-á dizer que as metas representam a reintrodução dos objetivos, como afirma Scallon (2009, p. 126): “[...] à luz de muitos exemplos dados pelos autores, os standards de conteúdos assemelham-se aos objetivos de aprendizagem que se tornaram familiares [...]", podendo funcionar, de igual modo, como standards de performance (por vezes, denominados descritores). Se forem considerados objetivos finais e intermédios, as metas de aprendizagem tão-só equivalem a um documento estratégico de regulação do currículo nacional, sendo uma das suas mais fortes componentes, pois os planos curriculares são de natureza normativa e os programas tendem para uma manifesta desvalorização.

Um dos efeitos da abordagem centrada em standards nas escolas é o da instrucionalidade da educação, com tendência para a valorização do ensino face à aprendizagem e do resultado face ao processo, no regresso à ideia da pedagogia behaviorista de que a escola funciona bem desde que os resultados sejam concordantes com os comportamentos definidos. Não sendo uma caixa preta e nem tão pouco um depósito de conhecimento, a escola tem um contexto socioeconómico e as diferenças existentes não têm de ser uma consequência da aprendizagem.

Daí que, segundo Hargreaves e Fink (2007), alguns países se encontrem a descartar a estandardização e a alicerçar as práticas educativas em estratégias essenciais à melhoria, destacando-se estas medidas: redução da aplicação de testes estandardizados; perfilhação de uma postura menos punidora perante o baixo desempenho das escolas; reincorporação da diversidade educativa; valorização dos docentes de elevada qualidade; recompensação da liderança educativa que apadrinha e confere status aos dirigentes educativos.

\section{ESCOLARIZAÇÃO RESTRITA}

Em termos de organização curricular, as duas abordagens tem como denominador comum a imposição 
de uma escolarização restrita, em contradição com a revalorização constante da escola pelas missões que lhe são confiadas socialmente. Tal estreitamento curricular significa, por um lado, a abordagem de conteúdos considerados essenciais, padronizados pelos testes internacionais e definidos pelas práticas de ensino vinculadas a um core curriculum globalizado, e por outro, a um mimetismo curricular, ou seja, são as disciplinaschave, sujeitas a provas nacionais e com ponderação na avaliação final dos alunos ao nível de progressão na escolaridade, ou de entrada no ensino superior, que servem de referência às restantes disciplinas, sujeitandoas a uma imitação de desempenho.

$\mathrm{O}$ neotecnicismo das duas referidas abordagens origina o empobrecimento curricular ao nível da qualidade das aprendizagens, não sendo possível dizer que a qualidade esteja somente na excelência dos resultados estandardizados, entendendo-se como sustentável a afirmação de que o desempenho do aluno é uma variável pessoal, institucional, social, económica e cultural, uma vez que se torna impossível isolar apenas uma destas variáveis como se ela fosse a fórmula ideal para a resolução de um problema tão complexo. Neste sentido, os estudos seminais realizados na década de 1970 sobre a teoria da correspondência e a teoria da reprodução social (SILVA, 2000) não só continuam válidos na sua razoabilidade argumentativa das críticas que são feitas às políticas neoliberais, mas também ajudam a compreender as relações de poder que existem nas escolas e, acima de tudo, na construção ideológica do currículo. $\mathrm{Na}$ análise da realidade educacional norte-americana, Karp (2012, p. 436,) conclui: "A profunda desigualdade de raça e classe continua sendo o tendão de Aquiles da educação pública". Outros autores evidenciam que "[...] o currículo estreitou-se, a preparação para os testes substituiu a escolaridade mais ampla, a trapaça desenfreou-se, a ajuda para as escolas necessitadas é mais do que insuficiente, e a NCLB contribuiu para o crescimento de uma perniciosa via direta da escola para a prisão [...]" (GUISBOND, NEILL e SCHAEFFER, 2012, p. 408).

$\mathrm{O}$ intento de diminuir as diferenças de desempenho entre alunos de contextos socioeconómicos distintos é algo que tem fracassado com as abordagens centradas em resultados e em standards, continuando a existir, e de forma mais visível, as diferenças entre escolas e o acesso ao conhecimento, para além das formas de diferenciação curricular existentes ao nível do apoio pedagógico. No quadro de uma política e de práticas curriculares de igualdade, o apoio pedagógico é uma estratégia de democratização no sentido de permitir a progressão na escolarização. No quadro oposto, o apoio pedagógico torna-se numa estratégia de diferenciação negativa, pois admite-se como ponto de partida, tal como acontece com o princípio neoliberal de que o pleno emprego é um entrave ao funcionamento do mercado, que a igualdade das aprendizagens não se torna num objetivo do sistema educativo. Pode-se, assim, aumentar os alunos por turma, alargar o horário letivo dos professores, diminuir os custos ao nível dos recursos humanos, principalmente dos professores e de outros profissionais, reduzir o apoio pedagógico aos alunos e declarar, politicamente, que os professores são os principais responsáveis pelo desempenho dos alunos, fazendo-se depender a imagem da escola dos processos de avaliação externa, tanto dos que resultam das provas nacionais, quanto dos que estão ligados a modelos de avaliação externa de escolas.

Em consequência, a avaliação contribui de forma decisiva para as culturas da ansiedade, frustração e deceção, reconhecidas, por Lipovetsky (2012), para a sociedade contemporânea. Sustentado que "o sucesso escolar e a seleção das elites continuam amplamente determinadas pelo meio social de origem" (ibid., p. 38), o autor sustenta que "[...] o fracasso é tão humilhante quanto escandaloso: a escola tornou-se numa casa de decepção" (ibid., p. 38), tendo avariado como máquina de integração social, não só pela taxa de abandono e desistência que ainda se verifica, como também pelo défice de aprendizagens com que muitos alunos saem da escolarização obrigatória (OECD, 2012b).

Observando-se que as escolas reguladas pelo mercado não são melhores do que as escolas públicas, ainda que na construção da seriação de escolas em Portugal seja uma ideia contrariada, porque também construído a partir de opções estatísticas duvidosas e enganadoras, “[...] as condições de trabalho dos professores das escolas administradas por contrato têm piorado [...]" (FREITAS, 2012, p. 388). Existindo uma profunda desigualdade social e uma cavada diferença no desempenho dos alunos, há também uma elevada instabilidade profissional docente, uma vez que a lógica de mercado, assente na correlação positiva entre investimento e resultados, pressupõe que é possível manter essa situação com menos professores, tornando-se apenas necessário industriá-los na tecnicidade da avaliação.

Sendo duas vertentes interconectadas das políticas de "prestação de contas", as abordagens curriculares centradas nos resultados e nos standards conferem, para além dos aspetos mencionados na organização curricular e no trabalho docente, um outro estatuto escolar ao conhecimento. Partindo da questão "Qual é o conhecimento mais importante que os alunos devem adquirir na escola?", e reconhecendo, na linha de Grumet (1988) que currículo é o elo de conhecimento de ligação entre gerações, e distanciando-se também quer da abordagem centrada nas disciplinas, quer da abordagem centrada no aluno, quer ainda de modelos tecnicistas 
e ideológicos, Young (2013, p. 103) argumenta que a discussão em torno de currículo necessita de ser feita a partir de uma teoria do conhecimento. Do mesmo modo, Moreira (2013, p. 191) sublinha que é necessário “[...] expressar a valorização do conhecimento escolar, matériaprima do currículo" e que "ensinar conhecimentos é função e obrigação da escola; é parte crucial, mesmo, de sua função política". Reforçando que esse conhecimento escolar é o conhecimento poderoso, ou conhecimento teórico, que se distingue do conhecimento do quotidiano, ligado ao contexto dos alunos, e sendo sensível às críticas que lhe têm sido feitas, por exemplo, por Moreira (2013, p. 192) - que defende, também, que o foco na cultura tem contribuído para "[...] a discussão do processo de construção de identidades" -, Young (2013., p. 108) sustenta que o conhecimento poderoso é especializado no espaço das disciplinas e diferenciado "[...] a partir das experiências que os alunos trazem para a escola ou alunos mais velhos trazem para a faculdade ou universidade. Esta diferenciação é expressa em fronteiras conceituais entre a escola e o conhecimento quotidiano [...]", Giroux (1997) salienta esta ideia quando refere que os estudantes deveriam aprender de modo dialético e não de modo isolado e fragmentado, e que os alunos deveriam ser agentes críticos, uma vez que trazem para as escolas necessidades e habilidades concebidas no decurso do seu dia-a-dia.

Para tal, e segundo Giroux (1997), é preciso conceptualizar um currículo que tenha em atenção o discurso crítico sobre a qualidade e finalidade da escolarização, entretecido ao processo cultural e à construção das identidades. É preciso desenvolver um olhar mais amplo, por forma a enriquecer mais o campo do currículo do que o controlar.

Atualmente, uma das principais barreiras do currículo é torná-lo significativo e, ao mesmo tempo, atraente para os alunos. Para levar a cabo um currículo sedutor e ambicioso, é preciso um currículo-como-vida (SOUSA, 2012), um currículo que aborde conteúdos de relevância para os alunos, que não silencie as vozes que lhe pareçam dissonantes do discurso culturalmente padronizado, que propicie o diálogo entre as diversas mundividências presentes e desenvolva novos saberes e novas formas de compreensão da realidade.

Mas ao admitir que a resposta à interrogação "Qual o conhecimento?" é uma questão epistemológica e ao mesmo tempo de justiça social, será que os mecanismos que fazem funcionar o mercado do conhecimento tornam a escola mais poderosa para diferentes tipos de alunos?

Em resposta, Young (2013, p. 115) escreve que a mensagem política "de um currículo baseado no conhecimento é que as desigualdades na distribuição de recursos de todos os tipos devem ser reduzidas para que as oportunidades educacionais sejam realmente melhoradas - e que na expressão contemporânea é uma questão complexa".

Como o mercado, pela matriz analítica de Foucault (2010), estabelece a concorrência como princípio basilar e favorece a construção da desigualdade, é pertinente estudar de que modo o conhecimento, tal como no pensamento marxista se defendia para o dinheiro, é um mediador universal, mediador este que pode tornar-se inteligível se forem analisadas as práticas em si e não o referencial que existe como um universal, pois o método crítico consiste em "[...] não interrogar os universais [...]", mas a partir da decisão da inexistência dos universais saber que história se pode fazer" (ibid., p. 27).

Porque o neoliberalismo interfere na vida das escolas (TAUBMAN, 2009), tal como o faz a globalização (SPRING, 2009), porque, pela lógica de mercado, a escola é um negócio (PINAR, 2007), a identidade empresarial dos professores é “[...] individualista, competitiva, controladora e reguladora, [sendo] definida externamente e orientada por standards [...]" (SACHS, 2003, citada por DAY, 2006, p. 89), presentes nos testes que se têm tornado em ondas gigantes no sistema educativo e no interior das escolas. A busca obsessiva de uma performatividade curricular, com reflexos na desqualificação do trabalho docente, cada vez mais funcionarizado pelo cumprimento de tarefas burocráticas, origina a padronização das aprendizagens e a consequente formalização da avaliação externa, com tendência para que os resultados escolares se transformem no principal indicador da avaliação institucional.

\section{CONCLUSÃo}

As diferentes e concatenadas formas de governamentalidade curricular são fases de um mesmo processo de controlo das escolas, dos professores e dos alunos, tornando-se, quase sempre, as escolas em áreas frias de conhecimento (PAPERT, 2008) e os professores e os alunos em autómatos do ensino e da aprendizagem, mesmo nas escolas que têm por missão assumir a educação pública como um compromisso social. Segundo Papert (2008, p. 134), a escola deve ter em atenção que aprender não é o resultado de se ser ensinado e que "a meta é ensinar de forma a produzir a maior aprendizagem a partir do mínimo de ensino".

Para tal, as propostas de trabalho deviam contemplar atividades repletas de significado, uma vez que os alunos só são capazes de adquirir conhecimentos quando as suas regiões mentais "frias" são aquecidas pelo contacto com as suas regiões mentais "quentes". Por sua vez, o aquecimento das áreas "frias" implica a inovação das práticas pedagógicas e, consequentemente, um novo 
paradigma alicerçado na matética e não na didática. $\mathrm{O}$ princípio central da matética é aclarar ideias através das pesquisas, em grupo, por parte dos alunos, uma vez que práticas pedagógicas centradas em boas discussões e em "affair" promovem aprendizagens significativas. $\mathrm{Na}$ medida em que a aprendizagem precisa de tempo para fazer conexões a partir de conhecimentos já construídos, só assim a conseguiremos valorizar (PAPERT, 2008) e alcançar "uma aprendizagem profunda e ampla que satisfaça a nossa fome de crescimento humano e de aperfeiçoamento (HARGREAVES e FINK, 2007, p. 50).

Qualquer opção pela aprendizagem tem reflexos no trabalho docente. A este propósito, na análise que fazem da realidade brasileira e portuguesa e explorando os modos de subjetivação da profissão docente no contexto das políticas educativas neoliberais, Correia, Pereira e Vaz, (2012) argumentam que a desqualificação profissional provoca nos professores não só novas formas de sofrimento profissional, devendo ser citado que o mal-estar docente "[...] é considerado, na atualidade, como um dos problemas laborais de caráter psicossocial mais importante" (DAVID e QUINTÃO, 2012, p. 145), mas também práticas profissionais defensivas, algumas delas partilhadas pelos docentes quando subscrevem que "[...] o trabalho do professor é relativamente irrelevante na produção dos bons alunos"(CORREIA, PEREIRA e VAZ, 2012, p. 398).

Aliás, esta situação cria nos docentes uma relação de estranheza com os alunos, ganhando credibilidade a afirmação de que "o mundo escolar é percecionado como um mundo caótico, habitado por jovens incompetentes para exercerem o seu ofício de aluno" (ibid., p. 397). Nesta construção de uma lógica de culpabilização, em que os diferentes atores do sistema educativo se entreolham de dedo acusativo em riste, tende-se a ignorar os efeitos das políticas educativas e curriculares (LEITE e FERNANDES, 2010) na construção de um espaço escolar orientado para os resultados e edificado a partir de standards. A ênfase no ensino para os testes, na avaliação externa e nos resultados internacionais, para além de determinados saberes, não é uma realidade intrínseca à escola e à educação que nela se veicula através do currículo, tão-só uma linguagem de prestação de contas e responsabilização, que cria e desenvolve estratégias públicas de culpabilização de pais, alunos e professores. Esta situação pode agravar-se ainda mais quando os professores atribuem a si próprios a missão prioritária de "[...] desenvolver um currículo, têm um currículo na mão que lhes é entregue e a isso não podem fugir [...]" (CORREIA, PEREIRA e VAZ, 2012, p. 399).

Esta tendência profissional resulta, em parte, como referimos ao longo do texto, do modo como o conhecimento é perspetivado e dos níveis de autonomia de que as escolas e os professores dispõem no quadro das decisões curriculares. Relativamente ao que é ensinado e aprendido nas escolas, os contributos de Young (2010; 2013) são pertinentes, ainda que a defesa de um conhecimento poderoso pode estar na base da sustentação de uma abordagem centrada nos testes.

Assumindo uma posição de síntese entre a revalorização do conhecimento escolar e a consideração das escolas como espaços de crítica cultural, Moreira (2013, p. 192) assume:

A escola precisa constituir-se em espaço de crítica cultural, de pesquisa e de atuação formativa para o trabalho. Precisa estar atenta às rápidas mudanças que ocorrem na sociedade contemporânea. Precisa estar atenta aos desenvolvimentos tecnológicos que marcam nossa época. Contudo, precisa analisar, a persistência na sociedade, da desigualdade e da opressão. Precisa renovar-se. Precisa expressar propósitos de inovação que não se restrinjam à modernização, à supervalorização das novas tecnologias, à adesão impensada ao novo, à aparência, ao acessório, a mudanças simplesmente epidérmicas. Não custa insistir que não haverá inovação sem a modificação do pensamento, das crenças, dos hábitos e das atitudes dos professores. Mas isso implica respeitar e valorizar devidamente esses profissionais.

Por último, a escola necessita de ser repensada pelos efeitos da globalização, enquanto expressão de políticas e culturas de convergência e padronização da realidade social, no modo como os sistemas oficiais tendem não só a burocratizar os professores, mas também a tornar os alunos em consumidores de aprendizagens apressadas, com vista à otimização dos resultados medidos por referenciais de produtividade, largamente influenciados pela racionalidade económica. A globalização interseta, assim, as políticas de educação na forma de políticas viajantes, definindo processos e práticas de avaliação que conduzem à performatividade das aprendizagens e à desqualificação docente.

\section{REFERÊNCIAS}

AFONSO, Almerindo. Para uma concetualização alternativa de accountabilitty em educação. Educação \& Sociedade, v. 33, n. 119, p. 471-484, 2012.

ANDERSON-LEVITT, Kathryn M. Globalization and curriculum. In: CONNELLY, F. Michael (Ed.). The Sage handbook of curriculum and instruction. Los Angeles: Sage, 2008, p. 349-368.

BROOKE, Nigel; SOARES, José Francisco. Pesquisa em eficácia escolar. Origem e trajetórias. Belo Horizonte: Editorial UFMG, 2008.

CHARLOT, Bernard. Educação e globalização. Uma tentativa de colocar ordem no debate. Sísifo. Revista de Ciências da Educação, v. 4, p. 129-136, 2007.

CORREIA, José Alberto; PEREIRA, Luísa Álvares; VAZ, Henrique. Políticas educativas e modos de subjetivação 
da profissão docente. Cadernos de Pesquisa, v. 42, n. 146, p. 368-387, 2012.

DAVID, Isabel Carmo; QUINTÃO, Sónia. Burnout em professores: a sua relação com a personalidade, estratégias de coping e satisfação com a vida. Revista Científica da Ordem dos Médicos, v. 25, n. 3, p. 145-155, 2012.

DAY, Christopher. A paixão pelo ensino. Porto: Porto Editora, 2006.

FOUCAULT, Michel. Nascimento da biopolítica. Lisboa: Edições 70, 2010.

FREITAS, Luiz Carlos. Os reformadores empresariais da educação: da desmoralização do magistério à destruição do sistema público de educação. Educação \& Sociedade, v. 33, n. 119, p. 379-404, 2012.

GIROUX, Henry A. Os professores como intelectuais: rumo a uma pedagogia crítica da aprendizagem. Porto Alegre: Artes Médicas, 1997.

GRUMET, Madeleine R. Bitter milk. Women and teaching. Amherst. The University of Massachusetts Press, 1988.

GUISBOND, Lisa; NEILL, Monty; SCHAEFFER, Bob. A década de progresso educativo perdida sobre a NCLB: que lições tirar deste fracasso político? Educação \& Sociedade, v. 33, n. 119, p. 405-430, 2012.

HARGREAVES, Andy; FINK, Dean. Liderança sustentável. Porto: Porto Editora, 2007.

KARP, Stan. Desafiar a reforma escolar empresarial e dez sinais esperançosos de resistência. Educação \& Sociedade, v. 33, n. 119, p. 431-454, 2012.

LEITE, Carlinda; FERNANDES, Preciosa. Desafios aos professores na construção de mudanças educacionais e curriculares: que possibilidades e que constrangimentos? Revista Educação-PUCRS, v. 33, n. 3, p. 198-204, 2010.

LIPOVETSKY, Gilles. A sociedade da decepção. Lisboa: Edições 70, 2012.

LUNDGREN, Ulf. PISA as political instrument: one history behind the formulating of the PISA programme. In: PEREYRA, M. A.; KOTTHOFF, H.; COWEN, R. (Eds.). PISA under examination. Changing knowledge, changing tests, and changing schools. Rotterdam: Sense Publishers, 2011.

MARADAN, Olivier. L'espacecurriculaire entre horizon etplacher. In: AUDIGIER, F.; TUTIAUX-GUILLON, F. (Dir.). Compétences et contenus. Les curriculums en questions. Bruxelles: De Boeck, 2008, p. 65-84.

MAROY, Christian. Towards post-bureaucratic modes of governance. In: STEINER-KHAMSI, G.; WALDOW, F. (Eds.). World yearbook of education 2012. Policy borrowing and lending in education London. London: Routledge, 2012. p. 62-93.

MOREIRA, António Flávio. Os princípios norteadores de políticas e decisões curriculares. Revista Brasileira de Política e Administração da Educação, v. 28, n. 1, p. 180-194, 2013.

OECD, Reviews of evaluation on and assessment in education in Portugal. Main conclusions, 2012a. Disponível em: <http:// www.oecd.org/education/preschoolandschool/50077677.pdf $\$$. Acesso em: 29 nov. 2012.

OECD, PISA 2012 Assessment and Analytical FrameworkMathematics, Reading, Science, Problem Solving and Financial Literacy, 2012b. Disponível em: $<$ http://www.oecdilibrary.org/education/pisa-2012-assessment-and-analyticalframework 9789264190511-en>. Acesso em: 20 de abr. 2013.
PACHECO, José A. Discursos e lugares das competências em contextos de educação e formação. Porto: Porto Editora, 2011.

PACHECO, José A.; SEABRA, Filipa; MORGADO, José C.; HATTUM-JANSSEN, Natasha. Avaliação Externa. Para a referencialização de um quadro teórico sobre o impacto e efeitos nas escolas do ensino não superior. Porto: Porto Editora, 2014. p. 1-36.

PARPET, Seymour. A máquina das crianças: repensando a escola na era da informática. Porto Alegre: Artmed, 2008.

PENNER-WILLIAMS, Janet. Tested curriculum. In: KRIDEL, C. Encyclopedia of curriculum studies, v. 2, p. 878-879, 2010.

PEREYRA, Miguel A.; KOTTHOFF, Hans-Georg; COWEN, Robert (Eds.). PISA under examination. Changing knowledge, changing tests, and changing schools. Rotterdam: Sense Publishers, 2011.

PINAR, William. O que é a teoria do currículo? Porto: Porto Editora, 2007.

POPKEWITZ, Thomas. PISA: Numbers, standardizing conduct, and the alchemy of Scholl subjects. In: PEREYRA, M. A.; KOTTHOFF, H.; COWEN, R. (Eds.). PISA under examination. Changing knowledge, changing tests, and changing schools. Rotterdam: Sense Publishers, 2011. p. 31-46.

RIZVI, Fazal; LINGARD, Bob. Globalizing education policy. London: Routledge, 2010.

SCALLON, Gérard. L'évaluation des apprentissages dans uneapproche par compétences. Bruxelles: De Boeck, 2009.

SOBRINHO, José Dias. Avaliação. Políticas educacionais e reformas da educação superior. São Paulo: Cortez, 2003.

SOUSA, Jesus M. Currículo-como-vida. Disponível em: $<$ http://www3.uma.pt/jesussousa/publica.htm>. Acesso em: 20 maio 2012.

SPRING, Joel. Globalization of education. An Introduction. Taipei/Roterdam: Sense Publishers, 2009.

STEINER-KHAMSI, Gita. Understanding policy borrowing and lending. Building comparative policy studies. In: STEINERKHAMSI, G.; WALDOW, F. (Eds.). World yearbook of education 2012. Policy borrowing and lending in education. London: Routledge, 2012. p. 5-17.

SILVA, Tomaz Tadeu da. Teorias do currículo: uma introdução Crítica. Porto: Porto Editora, 2000.

TAUBMAN, Peter. Teaching by numbers. Deconstructing the discourse of standards and accountability in education. London: Routledge, 2009.

YOUNG, Michael. Currículo e conhecimento. Do socioconstrutivismo ao realismo social na sociologia da educação. Porto: Porto Editora, 2010.

YOUNG, Michael. Overcoming the crisis in curriculum theory: a knowledge-based approach. Journal of Curriculum Studies, v. 45 , n. 2 , p. $101-118,2013$.

\section{Notas}

1 Cf. <http://www.projavi.mec.pt/np4/projavi>.

2 Apud Hargreaves e Dean Fink, 2007, p. 72. Maurice Holt é o principal defensor do movimento das escolas lentas. Para mais informação, vide: $<$ http://www.pdkintl.org/kappan/k0212hol.htm>. Acesso a 24 de abril de 2013 .

Artigo recebido em setembro 2013.

Aprovado em novembro 2013. 